\title{
Urgences
}

\section{Le saut de l'ange (extrait)}

Denise Desautels

Numéro 33, octobre 1991

Poésies parallèles : France - Québec

URI : https://id.erudit.org/iderudit/025664ar

DOI : https://doi.org/10.7202/025664ar

Aller au sommaire du numéro

Éditeur(s)

Urgences

ISSN

0226-9554 (imprimé)

1927-3924 (numérique)

Découvrir la revue

Citer ce document

Desautels, D. (1991). Le saut de l'ange (extrait). Urgences, (33).

https://doi.org/10.7202/025664ar d'utilisation que vous pouvez consulter en ligne.

https://apropos.erudit.org/fr/usagers/politique-dutilisation/ 


\section{Le saut de l'ange (extrait)}

Denise Desautels

a Martha Townsend

Il faut commencer par revenir d'Irlande.

JACQUES DARRAS

\section{CETTE MAIN QUI ENLACE LAUUTRE}

À l'origine, il y a toujours une histoire vraie. La voix de Martha n'invente ni l'exil, ni le lien, ni la faille; elle convoque tous les signes, n'en épargne aucun; elle les prolonge en textures fécondes jusqu'à cette oreille attentive où ils séjourneront. Est-ce une pensée pourpre ou des murmures d'anges? C'est au creux de l'oreille que la magie commence, alors que l'apaisement n'est plus possible.

Voici que la terre tourne sans ciel au-dessus; voici que la langue, ce qu'il y a de chant dans la langue, en ralentit le mouvement. On a beau dire mémoire, on a la sensation soudaine que la lenteur organise le monde, son monde, différemment. Bien que vivement éclairés, les objets se taisent. 
48

Je reste dans l'attente, privée de bruits, hormis cette peur fidèle dans le champ du regard. Étonnamment la scène se transforme dès que mon corps s'accélère. Il faut tant de silence pour épuiser l'image vertigineuse de cette main était-ce la main ou le bras? - qui enlace l'autre. Qui de ma mère ou de moi résiste encore? Etrange que tout recommence sans cesse, que le geste, tel un objet muet, tombe à nouveau sous mes yeux, irréprochable.

Dans l'histoire vraie, il n'y a toujours que le ciel qui fuit sans conséquence. Plus tard la sphère déposée là, offerte au regard et au toucher, propose sa forme aux peines gigognes; plus tard encore, le ciel n'est plus indispensable. On ne s'intéresse qu'à la couleur, qu'à ce bleu intraduisible d'un peintre vénitien. 


\section{LE RADEAU DE LA MÉDUSE}

Que faire de cette main ou de ce bras, de cette main ou de ce bras faussement déployé, lorsque la voix de Martha se fond dans celle de la soprano? Le doute plane au-dessus des objets. Est-ce la texture, la couleur ou la forme qui fait tressaillir? Dit-on d'un paysage pourpre qu'il est douloureux? En somme l'alibi de la couleur déjoue le souvenir et le divertit.

Ma voix au milieu d'autres voix se tait. La couleur est une respiration. Nous avons en commun des mains et des bras qui se cramponnent à d'autres mains, d'autres bras, sur un radeau infini. Nos corps épris au centre du tableau résistent mal à l'étreinte et pourtant la condamnent. Tout autour, la terre privée de ciel tourne. Quelque chose soudain, un vert ou un bleu, déplace le regard. 
50

Avant, je traversais le monde sans savoir où j'allais. Il me fallait une urgence, quelque chose qui me pousse vers autre chose, un détournement, une distraction qui apaise; toujours ma main cherchait a polir et repolir les surfaces continues des objets; après, je restais assise pendant des heures à attendre que quelque chose - puisqu'il faut quelque chose se rompe à nouveau, le mouvement cyclique de l'oubli.

Aujourd'hui, quand la terre privée de ciel tourne, je ne cherche plus à savoir où je vais; absorbée dans toute voix qui avive le regard, je la laisse se répandre, irradier de ce côté-ci du monde et ainsi retarder le moment où les petites vérités intimes, insondables, étoufferont pour vrai l'hymne à la joie. 